\title{
Estimation of Diffuse Solar Radiation for Selected Cities in Nigeria
}

\author{
M. S. Okundamiya ${ }^{1}$ and A. N. Nzeako ${ }^{2}$ \\ ${ }^{1}$ Department of Electrical and Electronic Engineering, Ambrose Alli University, PMB 14, Ekpoma 310006, Nigeria \\ ${ }^{2}$ Department of Electronic Engineering, University of Nigeria, Nsukka 410001, Nigeria
}

Correspondence should be addressed to M. S. Okundamiya, st_mico@yahoo.com

Received 10 July 2011; Accepted 9 August 2011

Academic Editors: E. R. Bandala, A. C. Rastogi, and P. Tsilingiris

Copyright (C) 2011 M. S. Okundamiya and A. N. Nzeako. This is an open access article distributed under the Creative Commons Attribution License, which permits unrestricted use, distribution, and reproduction in any medium, provided the original work is properly cited.

\begin{abstract}
This study proposes a multivariable model of monthly mean daily diffuse solar radiation on horizontal surfaces for three cities (Abuja, Benin City and Katsina), in Nigeria. The estimation was based on a correlation between clearance index and diffuse to global solar radiation ratio and was computed using monthly mean daily data set for global solar radiation on horizontal surfaces. The predictive efficiency of the proposed model was compared with the observed values and those believed to be universally applicable. The results suggest that the existing methods could be replaced by the developed model for a diffuse solar radiation data generation scheme.
\end{abstract}

\section{Introduction}

Global solar radiation data on the earth's surface are required by engineers, agriculturists, and hydrologists. Their effective harnessing and utilization are of significant importance globally, especially at the time of rising fossil fuel costs and the environmental effects of fossil fuel, such as the climate change problems. The knowledge of diffuse solar radiation and its contribution to global solar radiation is of immense importance since an inclined surface besides getting direct beam of solar radiation also receives diffuse solar radiation (scattered plus reflected). Long-term mean values of hourly or daily beam and diffuse solar radiations on a horizontal surface are often required in many solar energy applications. For example, the computation of insolation on inclined surface requires the corresponding hourly or daily beam and diffuse solar radiation. Global and diffuse solar radiation data are not measured by the forty-five (45) meteorological stations in Nigeria [1]. In the absence of these data (measured global and diffuse solar radiation data) one has to rely on the available methods and also to develop new ones.

Several models have been proposed to estimate global solar radiation. Liu and Jordan [2] developed a theoretical method for deriving the mean hourly solar radiation from the mean daily total radiation, with the assumption that the atmospheric transmission is constant throughout the day, and this is independent of solar altitude. Page [3] developed a linear relationship between clearance index and diffuse to global solar radiation ratio, while Iqbal [4] proposed a linear relationship in terms of clearance index for estimating monthly mean diffuse solar radiation. Using collected data for five US stations and Liu and Jordan's curve, CollaresPereira and Rabl [5] developed an analytical expression for the ratio of hourly to daily solar radiation, in terms of sunset hour angle. Erbs et al. [6] and Muneer et al. [7] developed correlations between hourly diffuse and global solar radiation on a horizontal surface as a function of the clearness index. Ulgen and Hepbasli [8] correlated the ratio of monthly average hourly diffuse solar radiation to monthly average hourly global solar radiation with the monthly average hourly clearness index in form of polynomial relationships for the city of Izmir, Turkey. In another study, they [9] correlated solar radiation parameters (global and diffuse solar radiation) with respect to ambient temperature in the fifth order. In the absence of measured data, Ahmed et al. [10] applied Liu and Jordan's and Page models to estimate the global and diffuse solar radiation for Hyderabad and Sindh, Pakistan. Recently Okundamiya and Nzeako [11] proposed 
TABLE 1: Analysis of estimation (proposed and existing) models using five-year (2001-2005) monthly mean daily data obtained for the study locations.

\begin{tabular}{lccccccccc}
\hline \multirow{2}{*}{ Models } & \multicolumn{3}{c}{ MBE (kWh/m²/day) } & \multicolumn{3}{c}{ Error terms } \\
& Abuja & Benin City & Katsina & Abuja & Benin City & Katsina & Abuja & Benin City & Katsina \\
\hline Present study & -0.0012 & -0.0008 & -0.0097 & 0.0397 & 0.0340 & 0.0901 & 0.1021 & 0.0814 & 0.3578 \\
Liu and Jordan [1] & -0.1464 & -0.2374 & -0.0179 & 0.2348 & 0.2604 & 0.1366 & 2.6444 & 7.3567 & 0.4375 \\
Page [2] & 0.0647 & 0.0544 & 0.0540 & 0.0931 & 0.0828 & 0.1082 & 3.2072 & 2.8978 & 1.9114 \\
Iqbal [3] & 0.3849 & 0.2582 & 0.5136 & 0.4202 & 0.2964 & 0.5215 & 7.5819 & 5.8834 & 18.9162 \\
Erbs et al. [6] & 0.8927 & 1.1042 & 0.5246 & 0.9393 & 1.1099 & 0.5661 & 10.1357 & 32.5672 & 8.1787 \\
\hline
\end{tabular}

${ }^{*} t_{c(11,0.025)}=1.96$.

a temperature-based model for predicting the monthly mean global solar radiation on horizontal surfaces for Abuja, Benin City, Katsina, Lagos, Nsukka, and Yola, representing the six geopolitical zones in Nigeria. In another study, they [12] showed the predictive ability of the temperature-based model over the linear model [13] using Warri meteorological data.

In this study, an empirical model for estimating the monthly mean daily diffuse solar radiation on horizontal surfaces was developed for three different cities in Nigeria. The diffuse solar radiation was also estimated from other established models, and the results were compared with our estimated results. Figure 1 shows the study locations in Nigeria.

\section{Methods}

In order to get the best model for the study locations, besides the established models $[2-4,6]$, we proposed a second-order polynomial relationship between diffuse and global solar radiation of the form

$$
\bar{H}_{d}=\bar{H}\left(m_{1}+m_{2} \bar{K}_{T}+m_{3} \bar{K}_{T}^{2}\right),
$$

where $m$ is the empirical constant, $\bar{H}_{d}$ is the monthly mean daily diffuse solar radiation on a horizontal surface $(\mathrm{kWh} /$ $\mathrm{m}^{2}$ /day), $\bar{H}$ is the monthly mean daily global radiation on a horizontal surface $\left(\mathrm{kWh} / \mathrm{m}^{2} /\right.$ day $)$, and $\bar{K}_{T}\left(=\bar{H} / \bar{H}_{o}\right)$ is the monthly mean daily clearance index. The performance of the proposed model was evaluated using the $t$-statistic (TS), a statistical indicator proposed by Stone [14], Root Mean Square Error (RMSE), and Mean Bias Error (MBE). These indicators are mainly employed for the adjustment of solar radiation data [15-17]. Detailed analysis of RMSE, MBE, and TS is given in the literature [11].

The results of (1) were compared with the results proposed by Liu and Jordan [2], Page [3], Iqbal [4], and Erbs et al. [6]. The available parameters informed the choice of the selected models for comparison. We have also considered the ability of these models to generate data from limited mean values and the accuracy (quality) of their results. The accuracy of the results reported by the original authors and those published in reviews were proven satisfactorily.

2.1. Data. A twenty-two-year (1983-2005) monthly mean global and diffuse solar radiation data set on a horizontal

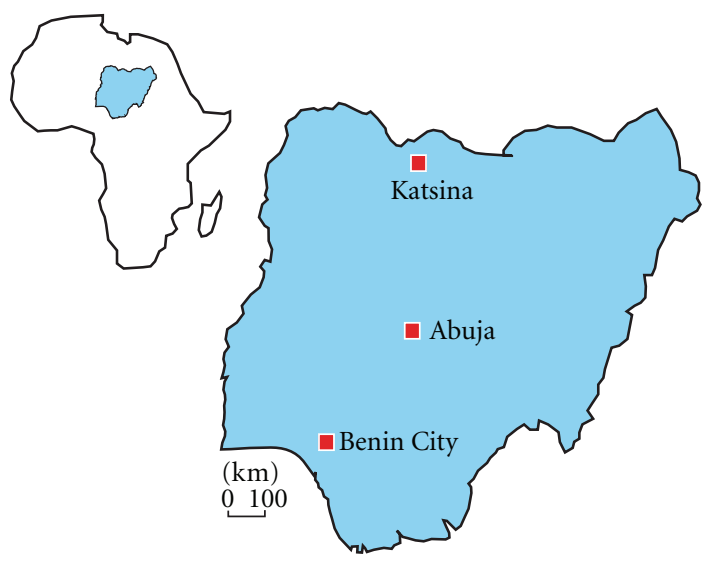

Figure 1: Map of study locations in Nigeria.

surface was obtained from the archives of National Aeronautics and Space Administration (NASA) [18] for three cities in Nigeria (Abuja, Benin City, and Katsina). The clearance index $\left(K_{T}\right)$ was obtained from the observed $H$ and computed $H_{o}$ for the study locations. $H_{o}$ is the daily extraterrestrial radiation on a horizontal surface $\left(\mathrm{kWh} / \mathrm{m}^{2} /\right.$ day $)$.

2.2. Simulation. We developed computer codes in MATLAB programming language to compute the empirical constants of (1) using the data discussed above (in Section 2.1). Our simulation results are illustrated in (2)-(4). The secondorder polynomial model was chosen since it produced the best fit. Regression analysis was performed on the proposed model (2)-(4) using Microsoft Excel 2007. Codes were developed in MATLAB to compute the other statistical indicators (MBE, RMSE, and TS). In this study, the performance of the TS was analyzed at the $95 \%$ confidence level. A stochastic analysis was performed on the estimation models (proposed and existing $[2-4,6]$ ) using five-year (2001-2005) monthly mean daily data. The results of the analysis are illustrated in Table 1 and Figure 2.

\section{Results and Analysis}

The results of the simulation of (1) are illustrated in (2)-(4). These results informed the proposal of an empirical model for estimating the monthly mean daily diffuse solar radiation 


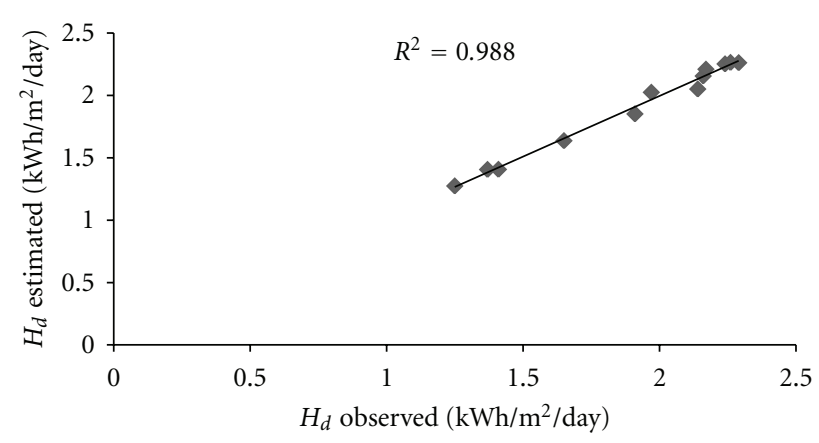

(a)

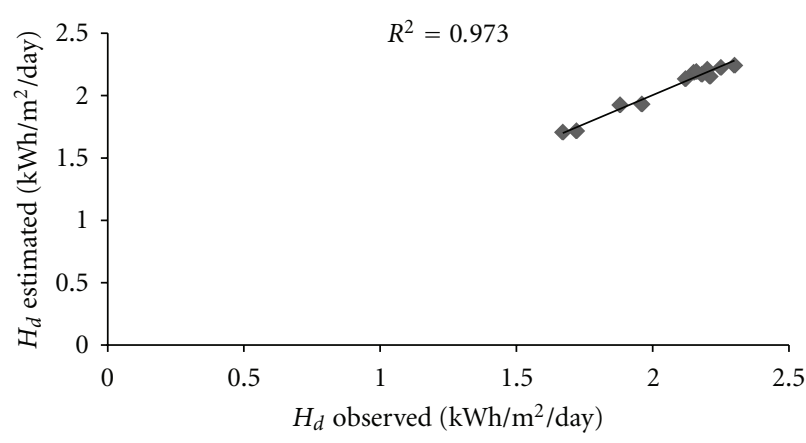

(b)

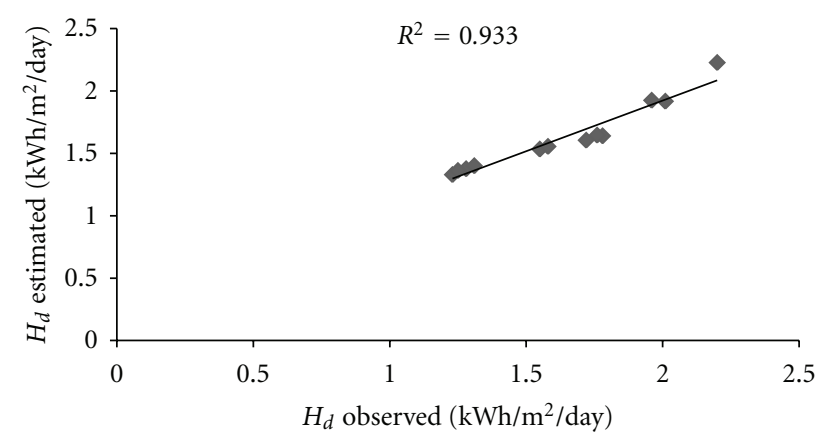

(c)

FIGURE 2: Correlation between the estimated and observed values of the monthly mean daily diffuse solar radiation using five-year (20012005) monthly mean daily clearance index: (a) Abuja, (b) Benin City, and (c) Katsina.

on a horizontal surface using clearance index for the locations investigated in this study as follows.

Model for Abuja:

$$
\bar{H}_{d_{\mathrm{ABJ}}}=\bar{H}\left(0.8733-0.5902 K_{T}-0.583 K_{T}^{2}\right) .
$$

Model for Benin City:

$$
\bar{H}_{d_{\mathrm{BEN}}}=\bar{H}\left(0.9467-0.809 K_{T}-0.4755 K_{T}^{2}\right) .
$$

Model for Katsina:

$$
\bar{H}_{d_{\mathrm{KAT}}}=\bar{H}\left(3.031-7.64 K_{T}-5.166 K_{T}^{2}\right) .
$$

Figure 2 shows the correlation between the estimated and observed values of the diffuse solar radiation using (2)-(4). The results of the stochastic analysis performed on the estimation models are illustrated in Table 1.

3.1. Comparison of Results. Figure 3 shows a comparison of the estimated values of monthly mean diffuse solar radiation obtained using (2)-(4) with those from the existing models. Figure 4 illustrates the comparison of the estimated values of the monthly mean diffuse solar radiation obtained using the proposed model with the observed values for the study locations.

\section{Discussion}

The following observations were deduced from the analysis of the results presented in Section 3. The empirical constants
( $m$ ) of the proposed model (2)-(4) vary for the study locations. This may be due to seasonal variations of the diffuse solar radiation caused apparently by the degree of cloud cover, atmospheric dust, and presence of water vapour and Ozone and so forth in the atmosphere which differs from one location to another. The correlation between the estimated and the observed values of the monthly mean daily diffuse solar radiation data as illustrated in Figure 2 is close to unity (0.933-0.988) for the proposed model. This is an indication of a good agreement of the estimated with the observed diffuse solar radiation.

The test of MBE provides information on the long-term performance of the proposed model. It is observed that Liu and Jordan's estimates are lower than the observed values. Iqbal and Page's estimates are higher, while Erbs et al.'s estimates are extremely higher than the observed values throughout the year as shown in Table 1. Almorox et al. [19] and Che et al. [20] have recommended that a zero value for MBE is ideal. This suggests significant underestimation (from Liu and Jordan's model) and overestimation (from Iqbal, Page, and the Erbs et al.'s models) of the diffuse solar radiation in the study locations. The proposed model has good long-term performance; the estimates compare favourably (with negligible underestimation) with their observed values. The result of this comparison is illustrated in Figures 3 and 4.

The test of RMSE provides information on the shortterm performance of the proposed model. The RMSE values 


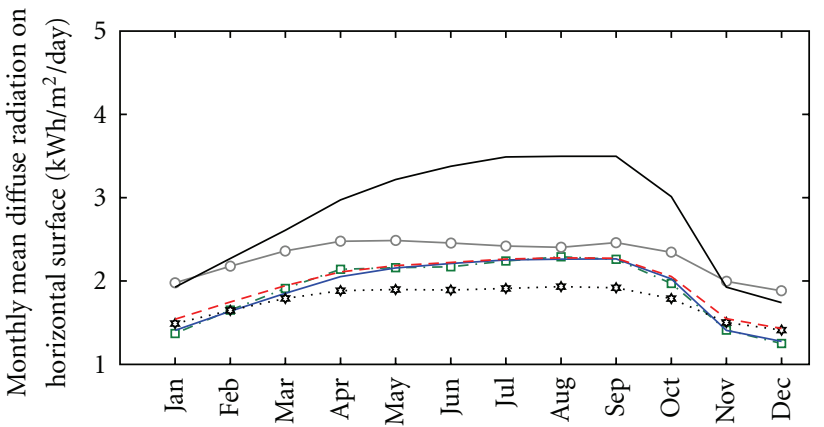

(a)

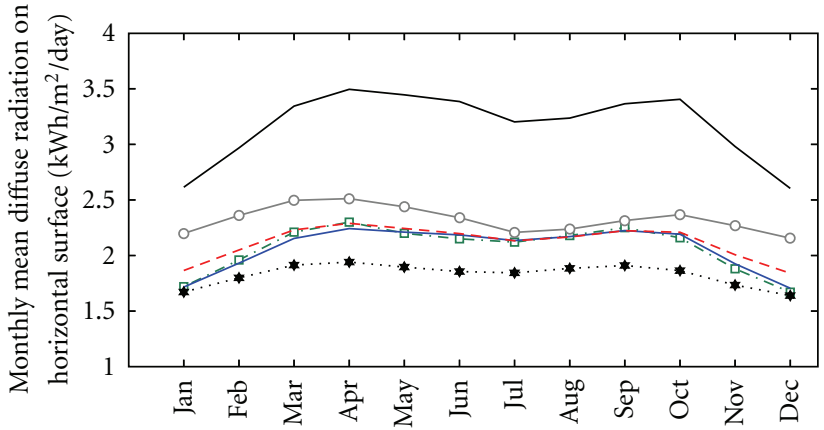

(b)

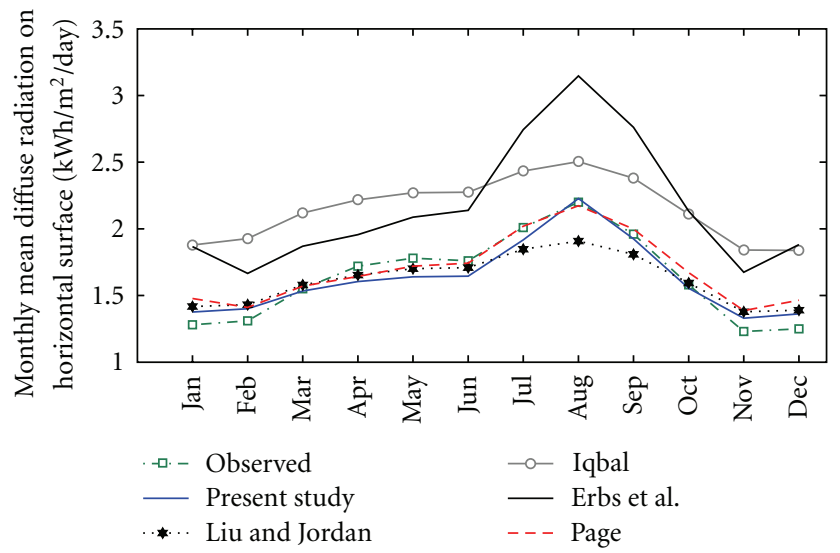

(c)

Figure 3: Comparison of the observed and estimated values of monthly mean diffuse solar radiation obtained using proposed (2)-(4) and existing models for (a) Abuja, (b) Benin City, and (c) Katsina.

vary from a minimum (from the proposed estimates) to a maximum (from Erbs et al.'s estimates). Low RMSE values are desirable $[19,20]$. This indicates that the proposed model has the best short-term performance for the study locations. The use of the MBE and the RMSE statistical indicators is not adequate for the evaluation of model performance $[16,17]$. This informs the use of the TS indicator.

The TS allows models to be compared and at the same time can indicate whether or not a model's estimate is statistically significant at a particular confidence level. It takes into account the dispersion of the results. The $t$-values of the Iqbal and Erbs et al.'s models lie outside the range of the critical $t$-values $\left(t_{c(0.025)}= \pm 1.96\right)$ for the study locations. These results indicate that their estimates should be rejected. The $t$-values of Page and Liu and Jordan's estimates lie within the range of the critical $t$-values only in Katsina. This suggests that their estimates are statistically insignificant in Abuja and Benin City. The $t$-values of our proposed models lie within the range of the critical $t$-values. That is, our estimated results are statistically significant at the 95\% confidence level. However, the low $t$-values of the proposed model demonstrate its good performance accuracy.

The variation of diffuse solar radiation with the months of the year is almost uniform throughout the year (Figure 4). The annual mean diffuse solar radiations in Abuja, Benin
City, and Katsina are $1.90,2.07$, and $1.64 \mathrm{kWh} / \mathrm{m}^{2} /$ day, respectively. The annual mean diffuse solar radiation estimates in Abuja, Benin City, and Katsina vary from a minimum of $1.76,1.83$, and $1.61 \mathrm{kWh} / \mathrm{m}^{2} /$ day (Liu and Jordan's estimates) to a maximum of $2.79,3.17$, and $2.16 \mathrm{kWh} / \mathrm{m}^{2} /$ day respectively (Erbs et al.'s estimates). Our proposed annual mean diffuse solar radiations are $1.90,2.07$, and $1.63 \mathrm{kWh} / \mathrm{m}^{2} /$ day, respectively. These compare favourably with the observed data as expected.

\section{Conclusion}

The study has demonstrated the availability of diffuse solar radiation on horizontal surface for Abuja, Benin City, and Katsina, employing clearance index. A second-order polynomial model was deduced from this and used to predict the monthly mean daily diffuse solar radiation, which was in agreement with the observed values. The study also verified the diffuse solar radiation models by Liu and Jordan, Page, Iqbal, and Erbs et al. The results indicate that the proposed model (2)-(4) compared favourably with the observed values in the three studied locations in Nigeria (Abuja, Benin City, and Katsina), while Page and Liu and Jordan's models only compared favourably with the observed values in Katsina. 


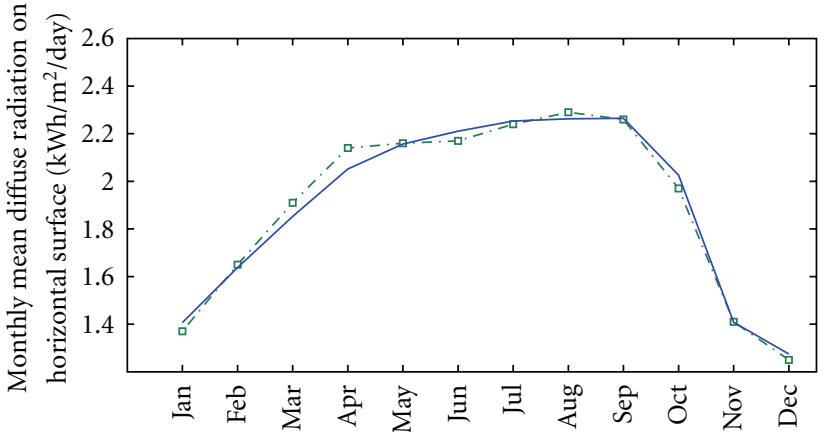

(a)

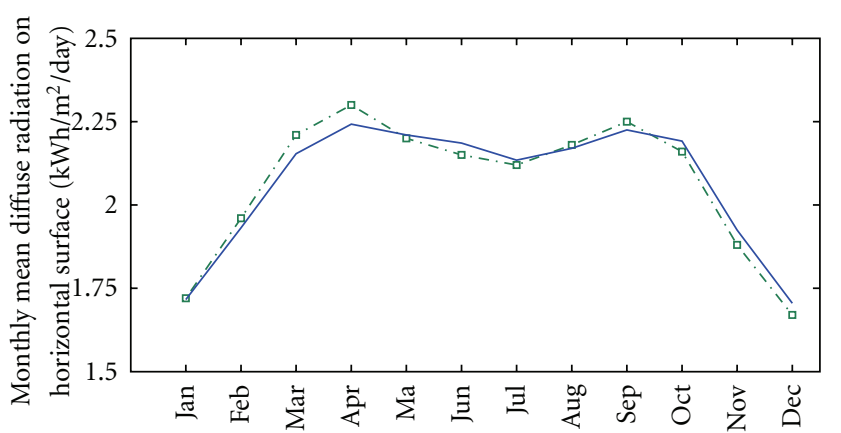

(b)

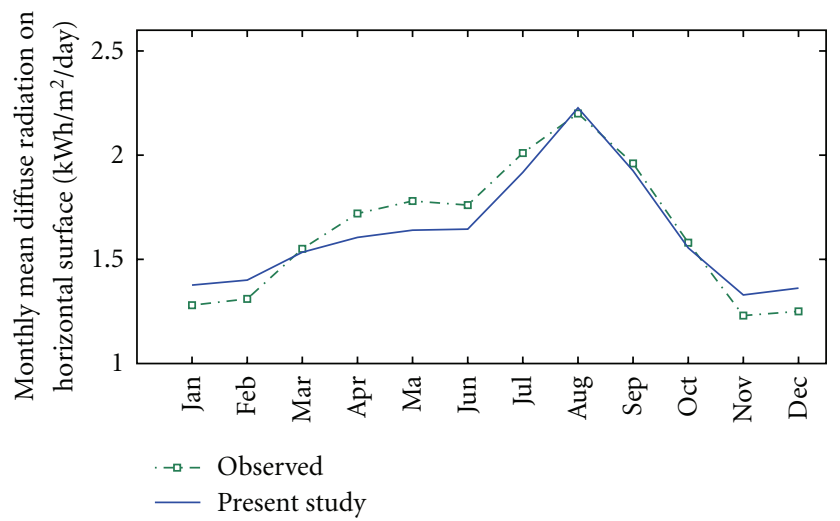

(c)

Figure 4: Comparison of the estimated values of the monthly mean diffuse solar radiation obtained using the proposed model with the observed values at (a) Abuja, (b) Benin City, and (c) Katsina, respectively.

\section{Acknowledgment}

This research was partially funded by ETF 2009 AST\&D Intervention (Reference no. AAU/REG/ETF.560/475).

\section{References}

[1] NIMA, "Archives of Nigerian Meteorological Agency (NIMA)," Oshodi, Lagos State, Nigeria, 2011.

[2] B. Y. H. Liu and R. C. Jordan, "Daily insolation on surfaces tilted towards equator," ASHRAE Transactions, vol. 3, pp. 526$541,1961$.

[3] J. K. Page, "The estimation of monthly mean values of daily total short-wave radiation on vertical and inclined surfaces from sunshine records for latitude $40^{\circ} \mathrm{N}-40^{\circ} \mathrm{S}$," in Proceedings of the United Nations Conference on New Sources of Energy, p. S/ 98, 1964.

[4] M. Iqbal, "A study of Canadian diffuse and total solar radiation data, part I. Monthly average daily horizontal radiation," Solar Energy, vol. 23, no. 2, pp. 169-173, 1979.

[5] M. Collares-Pereira and A. Rabl, "The average distribution of solar radiation-correlations between diffuse and hemispherical and between daily and hourly insolation values," Solar Energy, vol. 22, no. 2, pp. 155-164, 1979.

[6] D. G. Erbs, S. A. Klein, and J. A. Duffie, "Estimation of the diffuse radiation fraction for hourly, daily and monthlyaverage global radiation," Solar Energy, vol. 28, no. 4, pp. 293 302, 1982.
[7] T. Muneer, M. M. Hawas, and K. Sahili, "Correlation between hourly diffuse and global radiation for New Delhi," Energy Conversion and Management, vol. 24, no. 4, pp. 265-267, 1984.

[8] K. Ulgen and A. Hepbasli, "Prediction of solar radiation parameters through clearness index for Izmir, Turkey," Energy Sources, vol. 24, no. 8, pp. 773-785, 2002.

[9] K. Ulgen and A. Hepbasli, "Estimation of solar radiation parameters for Izmir, Turkey," International Journal of Energy Research, vol. 26, no. 9, pp. 807-823, 2002.

[10] M. A. Ahmed, F. Ahmad, and M. W. Akhtar, "Estimation of global and diffuse solar radiation for Hyderabad, Sindh, Pakistan," Journal of Basic and Applied Sciences, vol. 5, no. 2, pp. 73-77, 2009.

[11] M. S. Okundamiya and A. N. Nzeako, "Empirical model for estimating global solar radiation on horizontal surfaces for selected cities in the six geopolitical zones in Nigeria," Research Journal of Applied Science, Engineering and Technology, vol. 2, no. 8, pp. 805-812, 2010.

[12] M. S. Okundamiya and A. N. Nzeako, "A linear regression model for global solar radiation on horizontal surfaces in Warri, Nigeria," under review.

[13] C. Augustine and M. N. Nnabuchi, "Correlation between sunshine hours and global solar radiation in Warri, Nigeria," Pacific Journal of Science and Technology, vol. 10, no. 2, pp. 574-579, 2009.

[14] R. J. Stone, "Improved statistical procedure for the evaluation of solar radiation estimation models," Solar Energy, vol. 51, no. 4, pp. 289-291, 1993. 
[15] N. Halouani, C. T. Nguyen, and D. Vo-Ngoc, "Calculation of monthly average global solar radiation on horizontal surfaces using daily hours of bright sunshine," Solar Energy, vol. 50, no. 3, pp. 247-258, 1993.

[16] E. O. Falayi, J. O. Adepitan, and A. B. Rabiu, "Empirical models for the correlation of global solar radiation with meteorological data for Iseyin, Nigeria," International Journal of Physical Sciences, vol. 3, no. 9, pp. 210-216, 2008.

[17] A. M. Al-Salihi, M. M. Kadum, and A. J. Mohammed, "Estimation of global solar radiation on horizontal surface using meteorological measurement for different cities in Iraq," Asian Journal of Scientific Research, vol. 3, no. 4, pp. 240-248, 2010.

[18] NASA, "Surface Meteorology and Solar Energy Data and Information," 2010, http://eosweb.larc.nasa.gov/sse.

[19] J. Almorox, M. Benito, and C. Hontoria, "Estimation of monthly Angström-Prescott equation coefficients from measured daily data in Toledo, Spain," Renewable Energy, vol. 30, no. 6, pp. 931-936, 2005.

[20] H. Z. Che, G. Y. Shi, X. Y. Zhang, J. Q. Zhao, and Y. Li, “Analysis of sky conditions using 40 year records of solar radiation data in China," Theoretical and Applied Climatology, vol. 89, no. 1-2, pp. 83-94, 2007. 

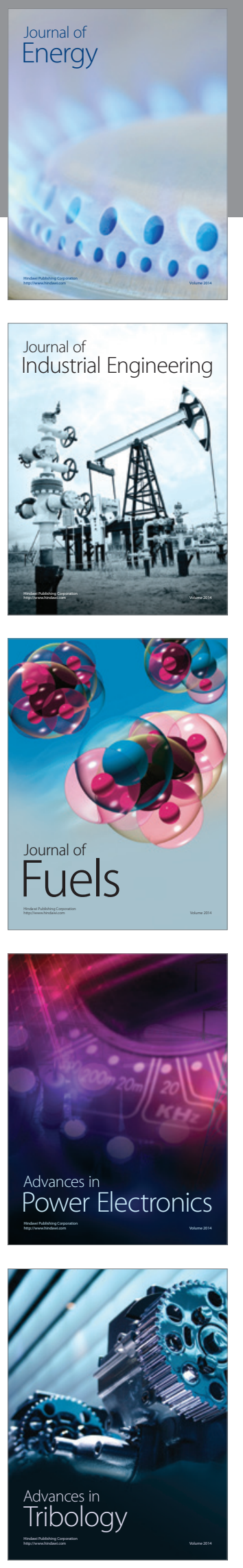
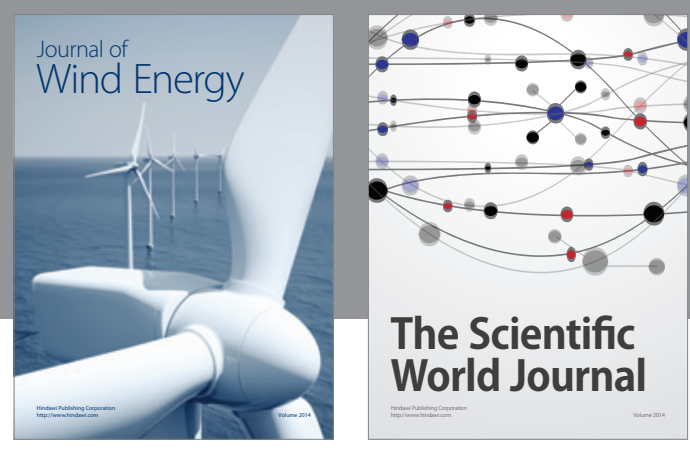

The Scientific World Journal

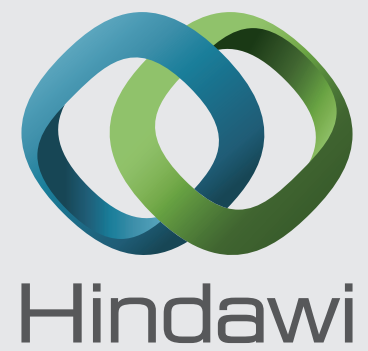

Submit your manuscripts at http://www.hindawi.com
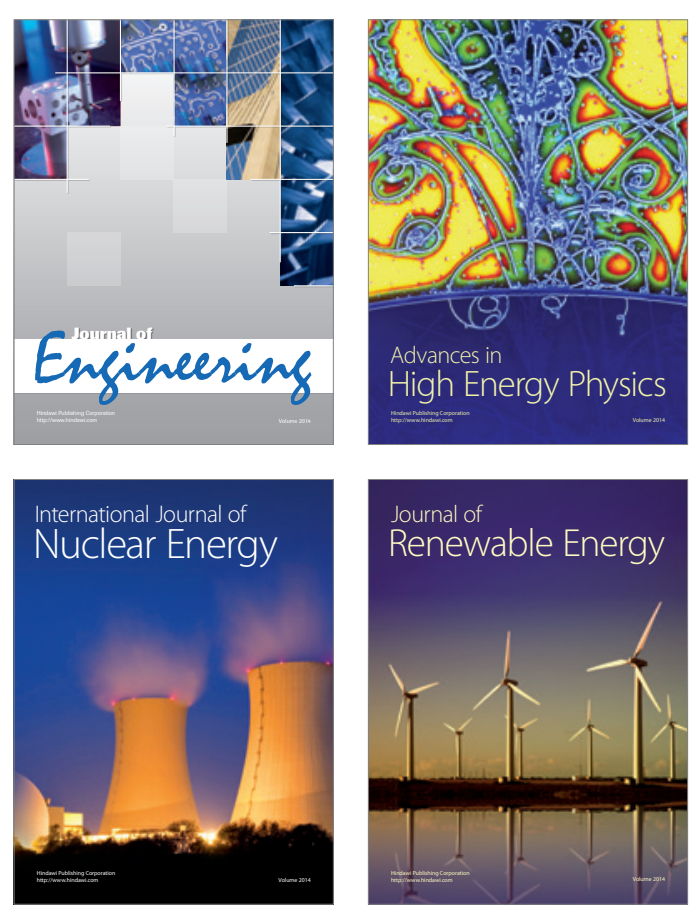

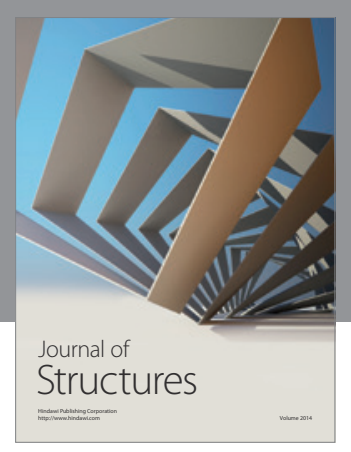

Rotating
Mechinery
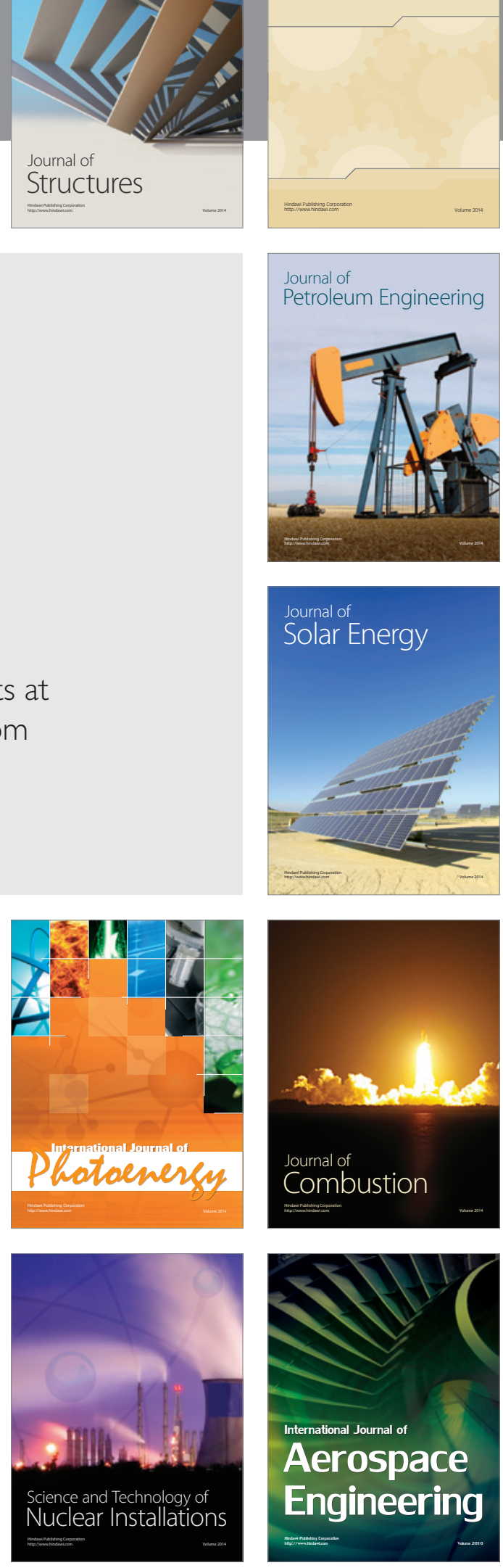